\title{
The Paradigm of OS and OCB: The Influence of Person- Environment Fit in Pakistani Banking Firms
}

\author{
Irum Mushtaq
}

MS in Business Administration, School of Business Administration, Qurtaba University, DIKhan, Pakistan

\section{Muneeb Awan}

Doctoral Student of Business Administration, School of Management, Xi'an Jiao tong University, China

\section{Ramsha Farooq}

Doctoral Student of Business Administration, School of Management, Xi'an Jiao tong University, China

\section{Jiyun Ma}

MSc in Management, UCD Michael Smurfit Graduate Business School, Dublin, Ireland

\begin{abstract}
Successful organizational socialization and organizational citizenship behavior are regarded as an important consequence to accomplish organizational performance. This study contributes to human resource management (HRM) by offering a contextualized model of OS, OCB and person-environment fit and its effectiveness in banking firms of Pakistan. The present research is to find the mediating effect of personenvironment fit on the relationship between organizational socialization and organizational citizenship behavior. The sample of this study was all banking employees from DIK district and total completed questionnaires collected back and used in the study were 372. Survey approach questionnaires were used for data collection. Instruments were adopted and used in present form without any modification. Correlation and hierarchical multiple regression were used for testing the hypotheses. It is found that there is a positive and significant relationship between organizational socialization, person-environment fit, and organizational citizenship behavior. It is found that person-environment fit does act as mediator on the relationship between organizational socialization and OCB. The findings provide new insights into Pakistani banking firms particularly DIK district Pakistan, directions for future research discussed.
\end{abstract}

Keywords: organizational socialization (OS), organizational citizenship behavior (OCB), person-environment (P-E) fit, Pakistani banking firms.

JEL Classification: Z1, D03, G21.

Cite as: Mushtaq, I., Muneeb, A., Farooq, R., Ma, J. (2019). The Paradigm of OS and OCB: The Influence of Person-environment Fit in Pakistani Banking Firms. Business Ethics and Leadership, 3(1), 18-33. http://doi.org/10.21272/bel.3(1).18-33.2019.

(C) The Authors, 2019. This article is published with open access at Sumy State University.

\section{Introduction}

Socialization tactics refer to the methods organizations use to help newcomers adapt to early entry experiences, to reduce uncertainty and anxiety associated with the reality shock of joining a new organization, and to acquire desired or necessary attitudes, behaviors, and knowledge (Bauer, Morrison, \& Callister, 1998; Cable \& Parsons, 2001; Jones, 1986; Van Maanen \& Schein, 1979).

Indicators of successful adjustment have included organizational attachment and commitment, job satisfaction, social integration, role clarity, task mastery, values congruence, and fit, among others (e.g., Bauer \& Green, 1998; Brett, Feldman, \& Weingart, 1990; Cable \& Parsons, 2001; Morrison, 1993a, 1993b; Wanberg \& Kamme yer-Mueller, 2000). Noe (2003) emphasized that the cost of sales could range between 50\% and 200\% of a worker's remuneration while investing the time in employing, preparing and the introduction of employees. The organizations provide a sophisticated environment where workers get information and resources where they can learn the latest modifications of working conditions (Watchfogel, 2009). The worker will go with the organizational socialization process where worker develops himself by acquiring the understanding of job requirements, adopts new job strategies and transforms himself according to new work roles and responsibilities or philosophy of work (Chao et al., 1994; Watchfogel, 2009). 
Similarly, in one another study, the basic attributes/contents of the labor were determined to be their language skills, policies affecting routine activities, performance standards and very significantly the values of any institution Chao et al. (1994). These segments of socialization have been directly proportional to the effective and efficient adjustment of the worker into the workplace. In a larger aspect, there is a positive correlation with, organizational socialization and organizational citizenship behaviors (Feldman).

The term OCB was first introduced by Dennis Organ and his colleagues in early 1980s. OCB defines that a worker is performed as a cohesive individual of his workplace or organization. Furthermore, unsuccessful organizational socialization which could not establish a good working relationship or adoption of new challenging roles will lead to high cost of grooming and training of employees and turnover costs (Bodoh, 2012). Consistent with principles of social studies have found that employees are more likely to engage in OCB when they have been treated fairly (Moorman, 1991), when they are given meaningful and satisfying work (Bateman \& Organ, 1983), when their supervisors inspire and motivate them (Grant, 2008), and when organizations are trustworthy, fulfill the promises they have made to employees, and show high levels of support (Turnley, Bolino, Lester, \& Bloodgood, 2003). OCBs are more likely to occur when employees feel pressured to engage in citizenship behaviors or see them as an expected part of their job (Bolino, Turnley, Gilstrap, \& Suazo, 2010). Finally, more recent work has highlighted the complex role that multiple motives, cognition, identity, and self-regulation processes may play in understanding how employee's process feedback regarding $\mathrm{OCB}$ and make decisions about engaging in future acts of citizenship (Lemoine, Parsons, \& Kansara, 2015).

Current research strives to investigate the association organizational socialization and organizational citizenship behavior. The remainder of this research study is to examine theoretical stances, to evaluate the difference between the relations of organizational socialization and organizational citizenship behavior, further we will examine the relationship of our mediating mechanism of organizational socialization. Next, we propose our theoretical framework and hypothesis development, analysis, and their results are briefly elaborated.

\section{Theoretical Framework and Propositions Development}

Given the scope of organizational socialization, person-environment fit, organizational citizenship behavior in Pakistani banking firms, we construct our conceptual research model:

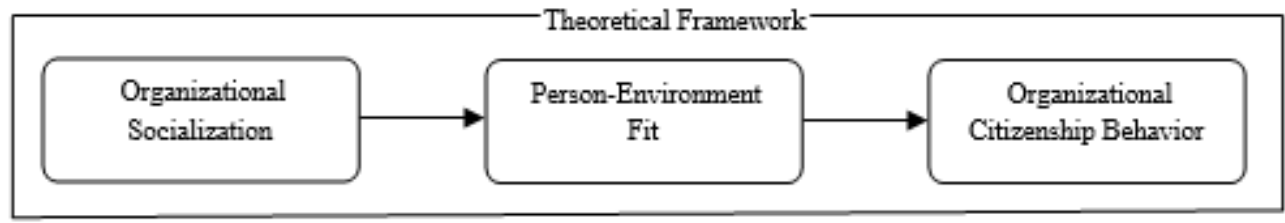

Figure 1. Conceptual Framework

\subsection{The propositions of this research study are as follows:}

Proposition 1: There is a significant relationship between organizational socialization and OCB.

Proposition 02: There is a significant relationship between organization socialization and person-environment fit.

Proposition 03: There is a significant relationship between person-environment fit and OCB.

Proposition 04: There is a mediation effect of person-environment fit on the relationship between organization socialization and OCB.

Proposition 05: There is a significant difference among demographics (age, marital status, and education) and research variables.

\section{Literature Review}

\subsection{Organizational Socialization}

Meaning of organizational socialization have advanced from general portrayal of "taking in the ropes" to a more point by point meaning of a "procedure and this procedure develops the employees of the organization in numbers of ways by increasing/enhancing their practical experiences, capacity for better performance and the social interaction quality of employees to effectively deal with other employees and organization and the 
ISSN (online) - 2520-6311; ISSN (print) - 2520-6761

employee becomes able to truly accept his role inside the organization" (Louis, 1980). Organizational socialization is an essential procedure by which individuals learn new skills, tasks, and organizational roles.

Organizational socialization is "a method of acquiring new jobs skills, abilities, and the adoption of the new working environment" (Kllein \& Weaver, 2000). Explanations of Klein and Weaver (2000) contribute to the past meanings given by Vaan Maannen (1978). Organizational socialization is established whenever employees go through an adjustment of the legislative limit (Wacchtfogel, 2009). Study of OS is an extensively broad field, which becomes even more complex with the structural variation of institutions. But all the dimensions of OS are the result/explanation of extensive study of its complete procedure which sheds light on two basic factors (Barbara B., 2005). Although in the current era OS has many dimensions explored by various researchers in different geographical areas of the world, its two areas have very much prominence in its process and content formation (Talya N. Bauer \& Berrin E., 2014). The research is about the phases where a worker or employees go through different phases and transform him from ordinary outsider to worth full member of the organization. (Talya N. Bauer \& Berrin E., 2014).The researcher put so much effort to identify the effective content of socialization "upon which areas we have to work for effective socialization.

Organizational socialization (OS), frequently known in corporate settings as onboarding, which refers to the learning process through which new employees assimilate the knowledge, skills, behaviors, norms, and values to become effective organizational members (Taormina, 2004). Applying OS leads to a number of crucial benefits for the organization such as loyalty among collaborators, greater work commitment, increased productivity, and permanence in the organization (Villavicencio, 2014). It has been found a relationship between the domains of OS (training, understanding, co-worker support, and future prospects) and engagement, specifically, it has been reported a positive correlation between the application of OS and high levels of work engagement among employees (Lisbona, Palací, \& Morales, 2009; Afsanepurak, Norouzi, Seyfari, \& Mohamadali, 2012).

The socialization process can take place formally via institutionalized socialization and training programs as well as informally through interactions among employees and observation. Indeed, how one is socialized is as important as the content of socialization (Ashforth et al., 2007) and the initial socialization experience has implications for perceptions, behaviors, and attitudes that remain throughout an individual's employment in the organization (Wesson and Gogus, 2005). Organizational socialization refers to the process of sharing experiences among employees, which is often done through observation, imitation, and practice (Jasimuddin, 2012). The majority of knowledge sharing occurs through the socialization process, which can be encouraged through the design of an organization.

Socialization provides a rich and meaningful platform for natural face-to-face interaction, thus enabling a medium where multiple senses and means (e.g., tone, eyes, body) can be used to convey knowledge (Karkoulian, Halawi, \& McCarthy, 2008). Socialization occurs in an informal and conducive environment within the organization, which brings employees closer (Schein, 1971; Wachtfogel, 2009). Van Maanen \& Schein (1979) framed scientific categorization of several strategies which explains the steps where individuals go through step by step from one level to next level and levels are arranged by the organizations for explaining the procedure of organizational socialization (Wachtfogel, 2009). The other important area of organizational socialization is a substance that what should be taught or studied and what should be the substance of the socialization that it could be easily understandable and depth of the process should be measured. In this manner, the query that what should be taught and studied must be responded to understand the effectiveness of socialization efficiently (Chao et al., 1994; Watchfogel, 2009).

As the industrialization and organizations made progress with the passage of time similarly the concept of socialization was also elaborated by many scholars as Fisher (1986) contributed significantly by explaining and expanding the dimensions of SOC. He pointed toward the various motives of employees inside the organization because of which his determination increases similarly the optimistic social environment of the organization, which enhances the cooperation of employees for the accomplishment of jobs, self-image of the individuals, which is highly dependent on the organization when organization regards its employees. These dimensions were then worked out for the development of a measurement scale so that they should be clearly identified. The standards and morals of organization objectives and principles and culture; beliefs of workers in the groups customs and relationships; and different assignments related to work, expertise required for performing the job, and broad information; and ability to change and or adopt new environment to inquire selfperceptions and intentions or motivation (Gogel, 2009). With the development of scale by Fisher (1986), it 
Business Ethics and Leadership, Volume 3, Issue 1, 2019

ISSN (online) - 2520-6311; ISSN (print) - 2520-6761

becomes the matter of high interest for the researchers to evaluate and work on various dimensions of socialization and to find out the real factors of the concept.

In the preceding years Chao et al. (1994)'s again contributed and highlighted several other factors which were to be the essential part of socialization these were the ability and aptitude of the individual/worker to efficiently work out the actual job/task, the capacity or capability of getting themselves equipped with the techniques information and self-sufficient with the needed abilities; people/ individuals, To identify the persons in the organizations that who can enable the newcomer to bring changes and groom the newcomer according to needs of the working environment; Politics /Legislative issues: Get employees prepare themselves with internal and external politics and get the understanding regarding power structure inside the organizations; Language employees get familiar with the professional terminologies, jingles, trademark, mottos, and abbreviations specialized for the organizations. Organization's goals and values/Authorities objectives \& Qualities; focused on the objectives of the organizations and get information about the organizations main objective and prepare themselves to achieve the organization's goals on the optimum level. History; this category is focusing on the individual's knowledge about the organization's traditions, background and past records according to the target environment prevailing inside the organization.

\subsection{Organizational Citizenship Behavior}

The foundational work on the OCB was carried out by Dennis Organ and today in the field of behavioral sciences and especially in the context of discussing the organization and the employee performances no one can ignore the significance of OCB. The basics provided by Katz's were further worked out by Organ in (1988), in which the fragmented/segmented the concept of OCB in to several features/characteristics which were that what incentives are being provided by the institution for the achievements of the worker, similarly what is the psychology of the institution for the better performance on the individual. According to Organ et al. (2006) increase in the output of workers and their time and work efficiency is the end result of OCB. Although the scholars have still not been united on a few single factors of OCB and it is still researched throughout the world in different organizational and environmental contexts. However Organ (1988) highlighted gave some basics for the phenomena of OCB and that was the OCB can never be installed through instructional procedures and it works as the theme like motivation and self-responsibility, also many organizations still have the deficiency of this concept in their practices which reduces the efficiency.

Ability to effectively perform and individual contributions are different concepts as compared with thinking of workers to contribute to the institute by themselves. This ability is related to the caring of the organization for its employees, which makes them loyal (Burton, 2003). Increase in the level of unemployment is also being related with the concept of OCB as because of increased turnover rate and because employees are not satisfied with one organization and they attempt to move toward other organization (Organ (1990). In spite of the developing acknowledgment of the OCB build, be that as it may, a few researchers have brought up issues about how OCB is theoretically characterized and measured (George and Brief, 1993; Graham, 1988; McAllister, 1991; Van Dyne, Cummings, \& Parks, 1992). Although the concept of OCB is directed toward every single employee and its construct attempts to evaluate the behavior at the individual level (Burton, 2003). The premise of OCBs depicted in studies from the field of organizational science. The concept of OCB explained by Organ relies on the extensive research and work of Chester (Yasin O., and Sinem E., 2015).

Barnard (1983) has attempted to explain the responsibilities of the supervisor on workers in his research. He explained Collaboration as a key indicator of organizational achievement. Barnard indicated that the employees who put extra effort to their work environment are fundamental for the existence of the organization, as the commission may be "something other than what's expected from viability, capacity, or estimation of individual commitments" (Barnard, 1938). A comparable definition is made by Daniel Katz regarding the subsequent advantage of participant employees was highlighted by Katz (1964) which attempted to give few essential facts. A review made by Katz comprised of three fundamentals which included "individuals should be encouraged to join and stay within the organization", "they should complete their part tasks in a tried and. the true form" and "A very inventive and unconstrained approach should be used in accomplishing organizational exercises which go much more than their particulars responsibilities" (Kaatz, 1964; Burrton, 2003).

Organizational citizenship behavior ideas include a variety of behaviors, such as employees, acceptance and assuming additional responsibilities, adherence of rules and procedures of the organization, maintaining and developing a positive attitude, and tolerance of work dissatisfaction and problems in conclusion. Based on the theories and organizational theories, organizational citizenship behavior helps organizational effectiveness and 
ISSN (online) - 2520-6311; ISSN (print) - 2520-6761

efficiency through the development of resources, innovation, and adaptability (Gholam Hosseini and colleagues, 2009). OCB means having a related impact on the effectiveness and efficiency of the organization. It contributes to the overall productivity and competitiveness of the organization (Sharma et al., 2011). In Shin and Kim (2010) two-component OCB model (i.e. altruism and generalized compliance), altruism is defined as voluntary acts of kindness without expectation of reward from others or the organizations. However, the bulk of existing researches on OCB are limited in traditional organizations, such as manufacturing, retail and health care industries. As the work environment is more knowledge-intensive and information-dependent, knowledge workers characterize organizational member.

As a result, with the dramatical change of the nature of work, the nature of OCB for modern workers is also likely to have changed (Dekas, Bauer, Welle, Kurkoski, \& Sullivan, 2013). And with concentrating on the altruism nature of OCB, researchers have redefined the dimensions of OCB for knowledge workers, including helping behavior, civic virtue behavior, voice behavior (Shin \& Kim, 2010), social participation behavior, employee sustainability behavior (Dekas et al., 2013). OCB is based on discretionary actions, the personal factors, especially attitudes with job and motivations, can be as more effective predictors of OCB compared with the other two aspects in IS setting. Recently, some researchers have paid attention to job satisfaction as a predictor of OCB (Ilies et al., 2009; Sawitri, Suswati, \& Huda, 2016).

On the basis of previous studies on OCB Organ (1988) suggested leniency not only in the formal structure of the organization but organizations must also provide employees with such environment that they may have the opportunity for giving their opinions. He is also of the view the cooperative environment requires strong social ties among the workers and the organization and for that purpose organizations must strive for the better social environment of the organization. The singular conduct that is optional, not simply or solely perceived through the formal structure of reward, and as a whole, promotes the competent and feasible work about any institution. It is common thinking that behavior requirements are secondary however these are the thoughts of the traditional school of thought which Leeds to the destruction of the organization.

Conduct of worker has many complexities to understand and only experienced supervisors can evaluate what is optimistic and what is negative in the conduct of workers. Smith et al., (1983) explained basic attributes from both sides i.e. from the administrative side and workers side about OCB. He stressed on the development of obedient nature of employees not by force but their will to respect and regard the instructions from the supervisor and he may submit his skills for the betterment. Similarly, he is also of the view that the administration must adopt the democratic style of leadership so that there must be an open relationship among employees and they must participate and contribute for the betterment of the organization. The concept was further fertilized by Organ (1988) by elaborating several other features. He kept the explanations of Smith et al. (1983) and enriched the concept with the moral obligations of the worker for his organization similarly he also highlighted the fact that when the administration or supervisor share his opinions then collaborating and associative social environment results in the elimination of political issues so productivity of the organization increases, he also highlighted the sportsmanship in such a way that employees may not criticize the small issues inside the organization and work for the higher achievements. The action which voluntarily used to contribute the individual or person about their task-related and provide a guideline about how to use new instruments which are used in ask performance and help them to achieve their task effectively and efficiently. The material, which used for task accomplishment but some time colleague cannot acquire to use it (Organ, 1988). Conscientiousness - practices rise above employment prerequisites in different territories, for example, participation, workload or the taking of breaks. Uprightness is an example of going admirably past insignificantly required levels of participation, timeliness, housekeeping, preserving assets, and related issues of interior support (Organ, 1988, 1990a, 1990b). Sportsmanship communicates eagerness to recognize not as much as perfect circumstances without grumbling and status to transcend the event. Kindness is the inclination to counsel with others and join points of view before making a move. The OCB well known as the self-sacrifice for other individual and they must do a respectable work in the organization it was suggested in order to achieve the enhanced productivity along with the enhanced social environment.

Altruism - deliberate exercises that assistance another person with a work issue - teaching a new contract how to use to make use to work with hardware, helping a collaborator get together with a build-up of work, getting materials a partner needs and can't get without anyone else's input (Body Organ, 1988). Conscientiousness practices above employment necessities in an assortment of regions, for example, nearness, workload or the taking of breaks. Scruple is a plan of heading great past negligibly required degrees of quality, timeliness, housekeeping, preserving assets, and related issues of inward upkeep (Body Organ, 1988, 1990a, 1990b). Sportsmanship communicates assurance to perceive not as much as perfect circumstances without grumbling 
Business Ethics and Leadership, Volume 3, Issue 1, 2019 ISSN (online) - 2520-6311; ISSN (print) - 2520-6761

and status to go up over the event. Affability is the sensation to check with others and join viewpoints before making a move. Courtesy incorporates endeavors to forestall business related issues with others (MacKenzie, Podsakoff and Fetter, 1993).

\subsection{Person-Environment Fit}

The conceptual phenomena of P-E fit are related to the integration of employees inside the organization. It plays a significant role in the overall enhancement of motivation toward the institute, also increases the commitment level of employees for their job and organization, and because of the P-E fit concept employee feels his carrier growth so his OCB level also enhances (Edwards, 2008; Chatman, 1991). As every individual has certain values and goals along with responsibilities and if these values don't match with the organization's environment than negative results originate in a number of different shapes for example lack of interest in employees behavior (Philip C., 2017). The concept of individual compatibility with the organization is very well researched but there is no specific or unique explanation of the concept as it varies from organization to organization and every organization has its own values, rules, and regulations throughout the world. According to Edward (2008) in case of organizational behavior, the significance of P-E fit can never be ignored as it acts as the backbone in predicting the behavior of the organization and its employees. According to Zimmerman, \& Johnson (2005), it is the measure of employee's association/attachment with his organization. According to Kristof (1996) the equivalence and similarities of both the organization and its workers in various aspects like similarity in the exchangeable needs, equality in values and opportunities provided by the organization for the enhancement of employee carrier.

The concept of PO-fit was highlighted by Schneider's (1987) who was of the view that every organization demonstrates certain values into the employees market because of which they join their ideal organizations, this match of employee ideas for the organization and the core values of the organization represents PO-fit. Whenever an employee found differences in the equivalent of their idea and the values of the institute then results in an increase in turnover rate. There is the difference in the approach of scholars in respect of PO-fit dimensions/measurements as many scholars have the approach of compatibility among goals between the two parties (Vancouver \& Schmitt, 1991) while many scholars have focused on the various individual and organizational values that to which extent they are similar. But the focus of both leads toward the evaluation of PO-fit of employees (Philip C., 2017). Many studies have considered specific dimensions of the concept but even if all the dimensions of PO-fit have been given full considerations, still the results cannot be totally generalized on every part of the world but only on specific geographic segment because every segment of the world represents different people with different ideas, skills, needs, capabilities and specifically different backgrounds (Bocchino et al., 2003).

Every individual is well versed with his self-capabilities for the effective performance of the job, along with that he also have certain motives like carrier development or his social plus psychic needs, along with all this every work wants to be regarded optimistically. Yasin O., Sinem E. (2015) proposed that every human resource must have to alert for these considerations in making their policies for the betterment of PO-fit. Previous studies have also explored the differences between the perceptions of an individual for the job and the organization. These perceptions differentiate from small to a very large extent. Sometimes the perception for the job is highly optimistic and at the same time perception for the organization is highly negative while sometimes the case is opposite (Lauver \& Kristof-Brown, 2001). Perception for the job is highly optimistic when the worker possesses the relevant skills and capabilities for his performance plus experience of the candidate matches with the relevant job.

According to (Cable and De Rue, 2002.) fitting of job is dependent on two factors first what are the needs of the employee which motivates him to join the organization and what different facilities that organization is providing them, second what are the demands of an organization like requirement of skills/capabilities inside the worker, and when both factors are at an equal level or of the same degree and are satisfying one another it could be termed as job-fit. However the organization fit is related with the easiness of worker in his dealing with policies, co-workers, his time secludes behavior of supervisor and the overall social environment of the organization (Cable \& Parsons, 2001). This is so much important that if there is single conflict among these factors then it forces the worker to find some other place and his motivation for the organization decreases (Cable and Derue, 2002).

In one another study of Mosley (2002), he identified that evaluation of performance/efficiency could also be done by closely monitoring the workers in groups and in their social gatherings where they openly communicate with each other. Group task provides the participatory and cooperative environment and it 
ISSN (online) - 2520-6311; ISSN (print) - 2520-6761

becomes very easy for the manager to identify the weaknesses and work on it as these group activities explain if there is variation between Job fit or PO fit.

\section{Methods, Results/Findings}

\subsection{Data Normality}

For data normality, skewness and kurtosis are used. According to Pallant (2010), the value of skewness and kurtosis is -3 and +3 . In Table 4.1, all the values of skewness and kurtosis for organization socialization, organization citizenship behavior, and person-environment fit are in range so this data is normal.

In addition, Table 4.1 has given mean and S.D values as well. So the highest mean for item 3 was recorded $(M=3.6351$, $S . D=0.59688)$ followed by item $1(M=3.5991, S . D=.57640)$ and lowest mean is recorded for item 2 was recorded $(M=3.4988, S . D=0.62069)$.

Table 4.1 Descriptive Statistics

\begin{tabular}{|l|c|c|c|c|c|c|c|}
\hline \multirow{2}{*}{} & $\mathbf{N}$ & Mean & Std. Deviation & \multicolumn{2}{c|}{ Skewness } & \multicolumn{2}{c|}{ Kurtosis } \\
\cline { 2 - 8 } & Statistic & Statistic & Statistic & Statistic & Std. Error & Statistic & Std. Error \\
\hline Org, Soc & 372 & 3.5991 & .57640 & -.461 & .127 & .262 & .253 \\
\hline OCB & 372 & 3.4988 & .62069 & -.170 & .127 & -.046 & .253 \\
\hline PEF & 372 & 3.6351 & .59688 & -.472 & .126 & .021 & .252 \\
\hline Valid N (listwise) & 372 & & & & & & \\
\hline
\end{tabular}

Source: Own elaboration

\subsection{Data Reliability}

This present study has reported reliable internal reliabilities of the instrument. Having reviewed the differences in the cultures of the Malaysia UK, USA and Pakistan it was necessary that these instruments are reliable in Pakistan context. This 'OS' questionnaire was used and validated earlier in Turkish research context by Ozdemir \& Ergun (2015). It was an intense need to extend this analysis in Pakistan context. The internal reliabilities were checked by ITC item-total correlation values. According to Field (2013) accepted a level of item-total correlation was 0.4 if the value of any item less than this cut off level should be deleted from the analysis. According to Bryman and Cramer (2001) alpha values at 0.7 is acceptable, alpha value 0.6 is questionable, 0.5 is poor and 0.8 is good and 0.9 is excellent. In this study, Cronbach alpha is recorded 0.929, which is above an acceptable level so this scale of cognitive style indicator is reliable in Pakistan context.

Table 4.2 Item-Total Statistics

\begin{tabular}{|c|c|c|c|c|c|}
\hline & $\begin{array}{c}\text { Scale Mean if Item } \\
\text { Deleted }\end{array}$ & $\begin{array}{c}\text { Scale Variance if Item } \\
\text { Deleted }\end{array}$ & $\begin{array}{c}\text { Corrected Item-Total } \\
\text { Correlation }\end{array}$ & $\begin{array}{c}\text { Cronbach's Alpha if } \\
\text { Item Deleted }\end{array}$ & Alpha \\
\hline OS1 & 82.78 & 174.898 & .599 & .925 & \\
\hline OS2 & 82.74 & 176.188 & .660 & .925 & \\
\hline OS3 & 82.78 & 176.919 & .586 & .926 & \\
\hline OS4 & 82.88 & 174.314 & .621 & .925 & \\
\hline OS5 & 83.02 & 173.318 & .616 & .925 & \\
\hline OS6 & 82.87 & 174.226 & .626 & .925 & \\
\hline OS7 & 82.87 & 172.619 & .650 & .924 & \\
\hline OS8 & 82.55 & 178.221 & .500 & .927 & \\
\hline OS9 & 82.65 & 176.975 & .564 & .926 & \\
\hline OS10 & 82.59 & 178.670 & .516 & .927 & \\
\hline OS11 & 82.65 & 176.461 & .604 & .925 & \\
\hline OS12 & 82.81 & 174.551 & .646 & .925 & \\
\hline OS13 & 82.71 & 177.765 & .582 & .926 & 0.929 \\
\hline OS14 & 82.80 & 177.663 & .574 & .926 & \\
\hline OS15 & 82.79 & 176.511 & .598 & .925 & \\
\hline OS16 & 82.74 & 175.594 & .593 & .925 & \\
\hline OS17 & 83.01 & 172.276 & .544 & .927 & \\
\hline OS18 & 82.80 & 175.196 & .591 & .926 & \\
\hline OS19 & 82.83 & 176.779 & .569 & .926 & \\
\hline OS20 & 82.61 & 181.567 & .387 & .929 & \\
\hline OS21 & 82.68 & 178.380 & .520 & .927 & \\
\hline OS22 & 82.69 & 179.652 & .472 & .927 & \\
\hline OS23 & 82.88 & 176.022 & .570 & .926 & \\
\hline OS24 & 82.97 & 176.437 & .556 & .926 & \\
\hline
\end{tabular}

Source: Own elaboration 


\subsection{Data Reliability Organizational Citizenship Behavior}

This present study has reported reliable internal reliabilities of the instrument. Having reviewed the differences in the cultures of the Malaysia UK, USA and Pakistan it was necessary to very that these instruments are reliable in Pakistan context. This 'OCB' questionnaire was used and validated in the Turkey ozdemir \& Ergun (2015). It was an intense need to extend this analysis in Pakistan context. The internal reliabilities were checked by ITC item-total correlation values. According to Field (2013) accepted a level of item-total correlation was 0.4 if the value of any item less than this cut off level should be deleted from the analysis. According to Bryman and Cramer (2001) alpha values at 0.7 is acceptable, alpha value 0.6 is questionable, 0.5 is poor and 0.8 is good and 0.9 is excellent. In this study, Cronbach alpha is recorded 0.900 , which is above acceptable level so this scale of OCB 'OCB' questionnaire developed by ozdemir \& Ergun (2015) is reliable in Pakistan context.

Table 4.3 Item-Total Statistics

\begin{tabular}{|c|c|c|c|c|c|}
\hline & $\begin{array}{l}\text { Scale Mean if Item } \\
\text { Deleted }\end{array}$ & $\begin{array}{c}\text { Scale Variance if Item } \\
\text { Deleted }\end{array}$ & $\begin{array}{c}\text { Corrected Item-Total } \\
\text { Correlation }\end{array}$ & $\begin{array}{l}\text { Cronbach's Alpha if } \\
\text { Item Deleted }\end{array}$ & Alpha \\
\hline OCB2 & 48.61 & 80.968 & .486 & .897 & \\
\hline OCB3 & 48.71 & 78.970 & .583 & .893 & \\
\hline OCB4 & 48.72 & 78.029 & .641 & .891 & \\
\hline OCB5 & 48.80 & 77.614 & .586 & .893 & \\
\hline OCB6 & 48.69 & 79.143 & .585 & .893 & \\
\hline OCB7 & 48.93 & 79.624 & .543 & .895 & \\
\hline OCB8 & 48.83 & 78.140 & .625 & .892 & \\
\hline OCB9 & 49.02 & 77.819 & .625 & .892 & 0.900 \\
\hline OCB10 & 48.99 & 76.397 & .636 & .891 & \\
\hline OCB11 & 48.71 & 79.491 & .581 & .893 & \\
\hline OCB12 & 48.81 & 78.926 & .528 & .895 & \\
\hline OCB13 & 48.46 & 80.628 & .550 & .895 & \\
\hline OCB14 & 48.75 & 78.573 & .631 & .892 & \\
\hline OCB15 & 48.72 & 79.163 & .589 & .893 & \\
\hline OCB16 & 48.91 & 78.927 & .510 & .896 & \\
\hline
\end{tabular}

Source: Own elaboration

\subsection{Data Reliability Person-Environment Fit}

Table 4.4 Item-Total Statistics

\begin{tabular}{|c|c|c|c|c|c|}
\hline & $\begin{array}{c}\text { Scale Mean if Item } \\
\text { Deleted }\end{array}$ & $\begin{array}{c}\begin{array}{c}\text { Scale Variance if Item } \\
\text { Deleted }\end{array} \\
\end{array}$ & $\begin{array}{c}\text { Corrected Item-Total } \\
\text { Correlation }\end{array}$ & $\begin{array}{c}\text { Cronbach's Alpha if } \\
\text { Item Deleted }\end{array}$ & Alpha \\
\hline PEF1 & 36.39 & 36.050 & .552 & .822 & \\
\hline PEF2 & 36.85 & 37.548 & .268 & .853 & \\
\hline PEF3 & 36.54 & 36.298 & .460 & .830 & \\
\hline PEF4 & 36.42 & 35.765 & .573 & .820 & \\
\hline PEF5 & 36.35 & 35.534 & .566 & .821 & \\
\hline PEF6 & 36.39 & 35.603 & .617 & .817 & \\
\hline PEF7 & 36.20 & 36.271 & .534 & .823 & 0.838 \\
\hline PEF8 & 36.14 & 36.857 & .492 & .827 & \\
\hline PEF9 & 36.27 & 35.362 & .636 & .815 & \\
\hline PEF10 & 36.19 & 36.036 & .594 & .819 & \\
\hline PEF11 & 36.13 & 36.898 & .489 & .827 & \\
\hline
\end{tabular}

Source: Own elaboration

\subsection{Correlation Analysis}

Correlations between OS and OCB are significant. It is strongly positive correlate, i.e. $r=0.769, \mathrm{p}=0.000$. Correlations between OS and Organization citizenship behavior is also significant. It means an increase in OS will lead to an increase in organizational citizenship behavior.

Table 4.5 Correlations

\begin{tabular}{|l|l|c|c|}
\hline \multicolumn{2}{|l|}{} & Org, Soc & OCB \\
\hline \multirow{3}{*}{ Org, Soc } & Pearson Correlation & 1 & $.769^{* *}$ \\
\cline { 2 - 4 } & Sig. (2-tailed) & 371 & .000 \\
\cline { 2 - 4 } & $\mathrm{N}$ & $.769^{* *}$ & 370 \\
\hline \multirow{3}{*}{ OCB } & Pearson Correlation & .000 & 1 \\
\cline { 2 - 4 } & Sig. (2-tailed) & 370 & 371 \\
\cline { 2 - 4 } & $\mathrm{N}$ & & \\
\hline \multirow{2}{*}{$* *$ Correlation is significant at the 0.01 level (2-tailed) } & \multicolumn{2}{|c|}{} \\
\hline
\end{tabular}


H2: There is a significant relationship between organization socialization and person-environment fit.

Table 4.6 Correlations

\begin{tabular}{|l|l|c|c|}
\hline \multicolumn{2}{|l|}{} & org_Soc & PEF \\
\hline \multirow{3}{*}{ org_Soc } & Pearson Correlation & 1 & $.741^{* *}$ \\
\cline { 2 - 4 } & Sig. (2-tailed) & & .000 \\
\cline { 2 - 4 } & $\mathrm{N}$ & 371 & 371 \\
\hline \multirow{3}{*}{ PEF } & Pearson Correlation & $.741^{* *}$ & 1 \\
\cline { 2 - 4 } & Sig. (2-tailed) & .000 & 372 \\
\cline { 2 - 4 } & $\mathrm{N}$ & 371 & \\
\hline \multirow{2}{*}{$* *$ Correlation is significant at the 0.01 level (2-tailed) } & & \\
\hline
\end{tabular}

Source: Own elaboration

Correlations between OS and person-environment fit are significant. It is strongly positive correlate. For example $\mathrm{r}=0.741, \mathrm{p}=0.000$. Correlations between $\mathrm{OS}$ and person-environment Fit is also significant. It means an increase in OS will lead to an increase in person-environment fit.

\section{H3: There is a significant relationship between person-environment fit and OCB.}

Table 4.7 Correlations

\begin{tabular}{|c|c|c|c|}
\hline & & PEF & OCB \\
\hline \multirow{3}{*}{ PEF } & Pearson Correlation & 1 & $.767 * *$ \\
\hline & Sig. (2-tailed) & & .000 \\
\hline & $\mathrm{N}$ & 372 & 371 \\
\hline \multirow{3}{*}{ OCB } & Pearson Correlation & $.767 * *$ & 1 \\
\hline & Sig. (2-tailed) & .000 & \\
\hline & $\mathrm{N}$ & 371 & 371 \\
\hline
\end{tabular}

Source: Own elaboration

Correlations between person-environment fit and organization citizenship behavior are significant. It is strongly positive correlate i.e. $\mathrm{r}=0.767, \mathrm{p}=0.000$. Correlations between $\mathrm{OS}$ and person-environment fit is also significant. It means an increase in person-environment fit will lead to organizational citizenship behavior.

\subsection{Regression Analysis}

H4: There is a mediation effect of person-environment fit on the relationship between organization socialization and $\mathrm{OCB}$.

Table 4.8 Run Matrix Procedure

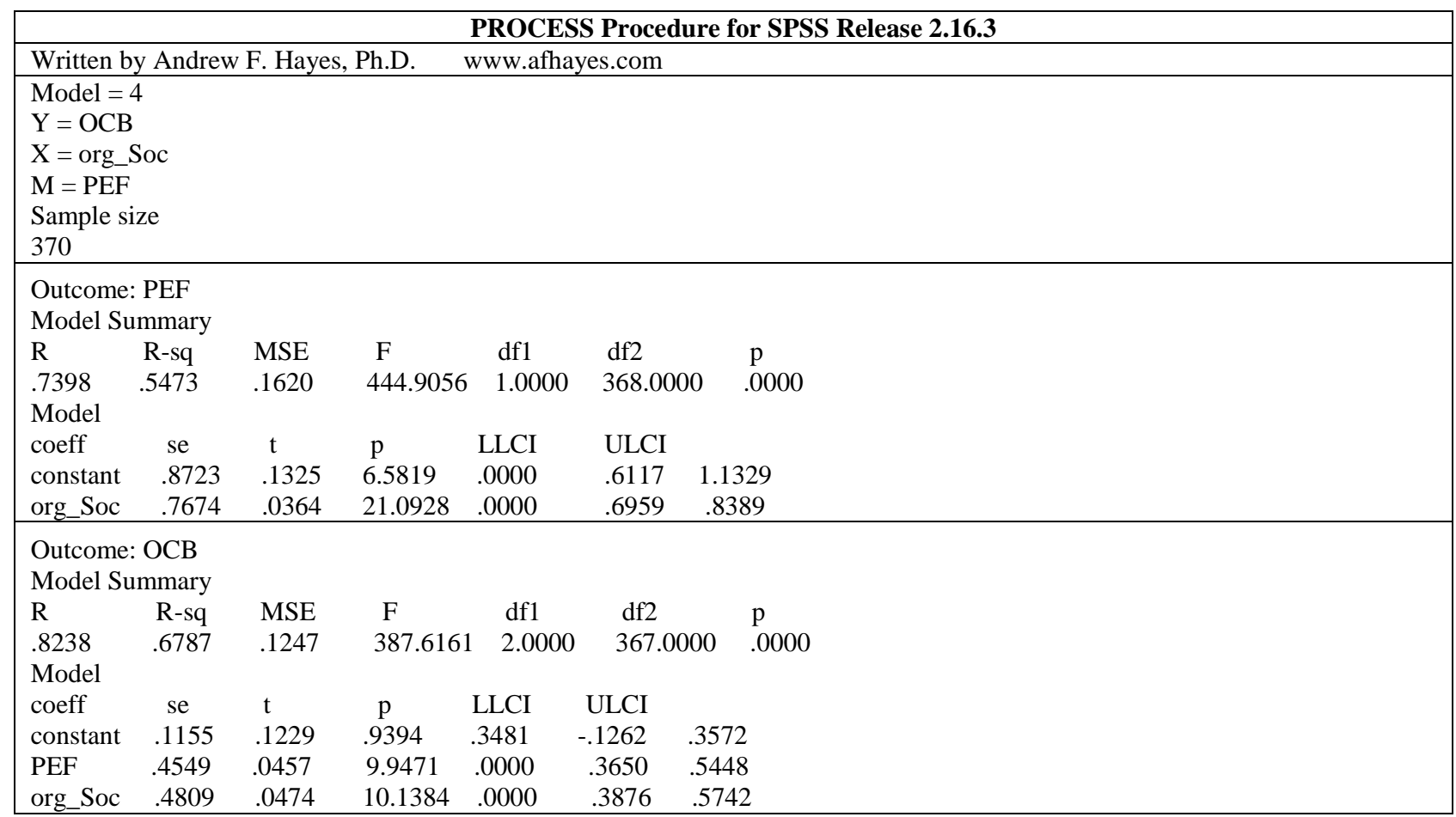


Table 4.8 (cont.). Run Matrix Procedure

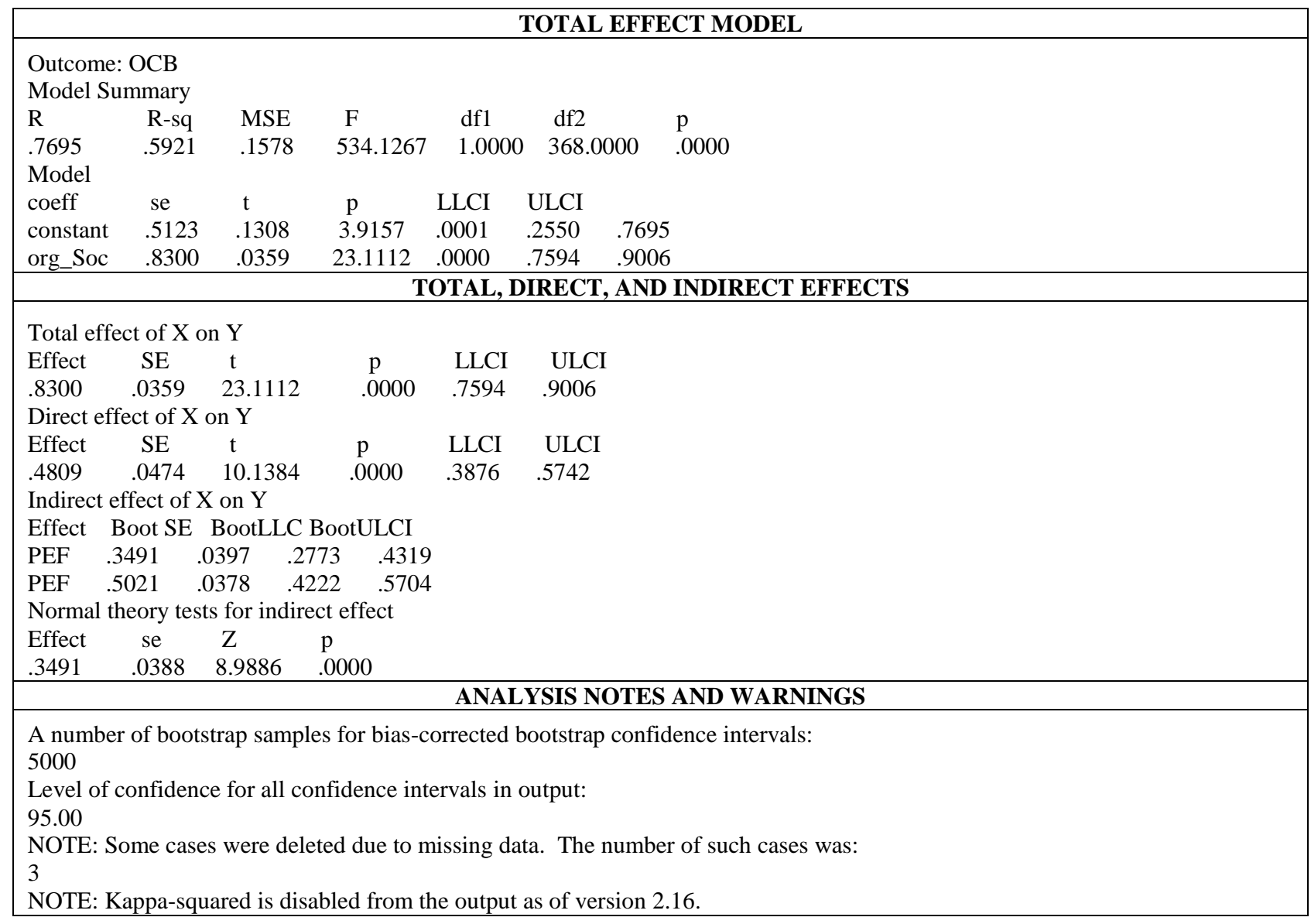

Source: Own elaboration

\subsection{Interpretation Mediation Results}

Barron and Kenny (1986) have given 4 rules for meditation later on these rules are followed by Hayes (2013) but the process for mediation is different in Hayes (2013). These rules are given as; first, there should be a relationship between the independent and mediating variable. Second, there should be a significant relationship between the mediator and dependent variable third if there is a significant relationship between independent and dependent variable also in presence of mediator then it is partial mediation if not then it will be full mediation.

On the basis of the above discussion, it is recorded that in this study OS and organization citizenship behavior have a significant relationship. Also, there is a significant relationship between person-organization fit and organization citizenship behavior. Also, there is a significant relationship between organization socialization and OCB in presence of mediator so it is concluded that person-environment fit is acting as a partial mediator between OS and organizational citizenship behavior.

\subsection{ANOVA Age}

H5: There is a significant difference between age and research variables.

Table 4.9 Test of Homogeneity of Variances

\begin{tabular}{|l|c|c|c|c|}
\hline & Levene Statistic & df1 & df2 & Sig. \\
\hline Org, Soc & .168 & 4 & 365 & .954 \\
\hline OCB & .562 & 4 & 365 & .691 \\
\hline PEF & 1.240 & 4 & 366 & .294 \\
\hline
\end{tabular}

Source: Own elaboration 
Table 4.10 ANOVA

\begin{tabular}{|c|c|c|c|c|c|c|}
\hline & & Sum of Squares & Df & Mean Square & $\mathbf{F}$ & Sig. \\
\hline \multirow{3}{*}{ Org, Soc } & Between Groups & 3.641 & 5 & .728 & 2.228 & .051 \\
\hline & Within Groups & 119.288 & 365 & .327 & & \\
\hline & Total & 122.929 & 370 & & & \\
\hline \multirow{3}{*}{ OCB } & Between Groups & 3.163 & 5 & .633 & 1.656 & .144 \\
\hline & Within Groups & 139.380 & 365 & .382 & & \\
\hline & Total & 142.542 & 370 & & & \\
\hline \multirow{3}{*}{ PEF } & Between Groups & 5.560 & 5 & 1.112 & 3.215 & .007 \\
\hline & Within Groups & 126.613 & 366 & .346 & & \\
\hline & Total & 132.173 & 371 & & & \\
\hline
\end{tabular}

Source: Own elaboration

For ANOVA first test of homogeneity of variance is checked the p-value of this test is insignificant so first condition if fulfilled so the researcher can proceed to ANOVA. In ANOVA F value for Socialization and PEF is significant it means that age can bring difference among socialization and person-organization fit so this hypothesis is partially accepted.

H5b: Marital status cannot bring any difference between all variables.

Table 4.11 Test of Homogeneity of Variances

\begin{tabular}{|l|c|c|c|c|}
\hline & Levene Statistic & df1 & df2 & Sig. \\
\hline Org, Soc & 2.624 & 3 & 366 & .050 \\
\hline OCB & 2.626 & 3 & 366 & .050 \\
\hline PEF & 1.989 & 3 & 367 & .115 \\
\hline
\end{tabular}

Source: Own elaboration

Table 4.12 ANOVA

\begin{tabular}{|c|c|c|c|c|c|c|}
\hline & & Sum of Squares & Df & Mean Square & $\mathbf{F}$ & Sig. \\
\hline \multirow{3}{*}{ Org, Soc } & Between Groups & 1.179 & 3 & .393 & 1.184 & .316 \\
\hline & Within Groups & 121.473 & 366 & .332 & & \\
\hline & Total & 122.652 & 369 & & & \\
\hline \multirow{3}{*}{ OCB } & Between Groups & .702 & 3 & .234 & .605 & .612 \\
\hline & Within Groups & 141.588 & 366 & .387 & & \\
\hline & Total & 142.291 & 369 & & & \\
\hline \multirow{3}{*}{ PEF } & Between Groups & .352 & 3 & .117 & .327 & .806 \\
\hline & Within Groups & 131.812 & 367 & .359 & & \\
\hline & Total & 132.164 & 370 & & & \\
\hline
\end{tabular}

Source: Own elaboration

For ANOVA first test of homogeneity of variance is checked the p-value of this test is significant for socialization and OCB but insignificant for PEF so first condition is not fulfilled for OS and OCB. So a researcher can proceed to ANOVA for PEF. In ANOVA F value for all variables is insignificant it means that marital status cannot bring difference among socialization and person-organization fit and OCB so this hypothesis is rejected.

H5c: Education Brings difference among research variables.

Table 4.13 Test of Homogeneity of Variances

\begin{tabular}{|l|c|c|c|c|}
\hline & Levene Statistic & df1 & df2 & Sig. \\
\hline Org, Soc & .411 & 4 & 366 & .801 \\
\hline OCB & 2.085 & 4 & 366 & .082 \\
\hline PEF & 2.587 & 4 & 367 & .037 \\
\hline
\end{tabular}

Source: Own elaboration

Table 4.14 ANOVA

\begin{tabular}{|l|c|c|c|c|c|c|}
\hline \multicolumn{2}{|c|}{} & Sum of Squares & df & Mean Square & F & Sig. \\
\hline \multirow{4}{*}{ Org, Soc } & Between Groups & 4.986 & 4 & 1.246 & 3.868 & .004 \\
\hline & Within Groups & 117.943 & 366 & .322 & & \\
\cline { 2 - 7 } & Total & 122.929 & 370 & & & \\
\hline \multirow{4}{*}{ OCB } & Between Groups & 3.912 & 4 & .978 & 2.582 & .037 \\
\hline & Within Groups & 138.630 & 366 & .379 & & \\
\cline { 2 - 7 } & Total & 142.542 & 370 & & & \\
\hline \multirow{3}{*}{ PEF } & Between Groups & 4.217 & 4 & 1.054 & 3.024 & .018 \\
\cline { 2 - 7 } & Within Groups & 127.956 & 367 & .349 & & \\
\cline { 2 - 7 } & Total & 132.173 & 371 & & & \\
\hline
\end{tabular}

Source: Own elaboration 
For ANOVA test of homogeneity of variance has fulfilled the condition for OS and OCB not for PEF. So a researcher can proceed to ANOVA for socialization and OCB, not for PEF. In ANOVA F value is significant it means that highlighted education can bring a difference in socialization and organization citizenship behavior. So this hypothesis is also partially accepted.

\section{Conclusions and Recommendations}

\subsection{Discussions}

This research consisted of five chapters. All the five chapters are discussed in detailed. The first chapter is the introduction chapter which includes the background of the study, then problem statement addressing the gaps in the research and also the objectives and hypotheses development are also addressed in this study. Follow with the significance of the study.

The second chapter consisted of all the models and theoretical overview of the theories and models of organizational Socialization, 'OCB' and personal environment fit. It has a critical review of all the past literature. Also, organizational Socialization, 'OCB' and personal-environment fit was discussed in detail according to facets wise.

The third chapter is very important it is research methodology. First of all research philosophies were discussed then followed by research design, population, sampling, data collection instruments and data collection methods were also discussed in this chapter. Different forms of statistical tests and software are discussed in this chapter.

The fourth chapter is empirical analysis. It started with data normality, data reliability, then mean standard deviation and percentages. Then inferential statistics were applied in which correlation, regression, a test of significances were used.

\subsection{Conclusions}

This study has several objectives and hypotheses. First of all the hypotheses were to check the relationship between the variables. It was found that all the variables, which were independent i.e. OS and OCB were positively and significantly correlated, Organization Socialization, Personal Environment Fit, and Organization Citizenship Behavior all variables are correlated hence all the hypotheses of relationship are accepted. There is significant Relationship between Organization Socialization and Person-Environment Fit.

Correlations between OS and person-environment fit are significant and strongly positive. There is a significant relationship between person-environment fit and OCB. Correlations between person-environment fit and organization citizenship behavior are significant and strongly positive.

There is a significant relationship between organization socialization and OCB in presence of mediator so it is concluded that person-environment fit is acting as a partial mediator between OS and organizational citizenship behaviors.

Regression results also strengthened the correlation results. An overall regression model was found a fit, $r$ square value contributed significantly upon OCB and there was no multicollinearity and no heteroscedasticity was found in the data overall data was normal.

Independent t-tests and ANOVA test were applied on the OS, OCB, and PEF. It was found that all the demographics were insignificantly related with research variables the only sector has a mean difference in the scores of the leadership effectiveness.

There is a significant difference among age and research variables For ANOVA first test of homogeneity of variance is checked the p-value of this test is insignificant so first condition if fulfilled so the researcher can proceed to ANOVA. In ANOVA F value for organization Socialization and PEF is significant it means that age can bring difference among socialization and person-organization fit so this hypothesis is partially accepted.

Marital status cannot bring any difference between all variables. In ANOVA F value for all variables is insignificant it means that marital status cannot bring difference among socialization and person-organization fit and OCB so this hypothesis is rejected. Education Brings difference among research variables, In ANOVA $\mathrm{F}$ value is significant it means that highlighted education can bring a difference in socialization and organization citizenship behavior. So this hypothesis is also partially accepted. 


\subsection{Contributions}

This study has contributed successfully to the theory of OS and the theory of organizational citizenship behavior and personal environment fit. These two theories are related to each other and also this study has bridged these two theories. Also, this study has contributed to the literature of OS and creating 'OCB' and also Personal Environment Fit.

\subsection{Implication for the Practitioners}

This study has several implications for practitioners i.e. practitioners can raise awareness in workshops, seminars, and conferences and also help the employees and as well as leaders to improve their decision-making styles and also improve their Organization Socialization, Organization Citizenship Behavior, and Personal Environment Fit.

\subsection{Possible Implication at Pakistani Banking Firms}

This study provides a new insight to Pakistani banking firms particularly banking firms in DIK district, that DIK district banking firms (for example, Bank Alfalah, Habib Bank, Habib Metropolitan Bank, Muslim Commercial Bank, Askari Bank, etc) should extend this conceptual phenomenon of Organization Socialization, organizational citizenship behavior, and Person-Environment Fit into their practical implication for successful banking future. "The goals of my organization are also my goals" the theme of this question in our questionnaire, should be kept in mind of every individual who is working in banking firms (specifically DIK district banking firms) for successful future at the individual level as well as for organizational perspective.

In Addition, this study provides new insight to make a vital contribution in the banking sector as conducting analysis to banking employees. The relationship between OS and OCB and impact of personal environment fit to this relationship can be studied with different samples. Moreover, this study aims to enable employers (Managers) to analyze the socialization skills of their employees and to know how they react to stress and how they tackle stressful situations. With the help of this study, employers can evaluate the missing characteristics of socialization contents of their employees. Employers should highlight their lacking social skills and while arranging orientation and training programs and eradicate mainstream issues.

\subsection{Limitations of the Study}

This study has a few limitations. The first is a very small sample size is taken from one city. So the findings of this study are only generalized able to this small sample size second the findings are only generalized to banking employees because data were collected from banks. Third, this study has been used only one-time data collection next future studies can use longitudinal way of data collections. Data were collected using a single method.

\subsection{Recommendations for the Future}

Leadership style and Job satisfaction can be used in future banking studies. More dimensions of Organization Socialization, Organization citizenship behavior, and Person-Environment Fit can be used as a mediator, moderator, and independent variables. Big sample size should be used in order to get more accurate and biased free results. Mix methods can be used to get more interesting results.

\section{References}

1. Allen, T.D., McManus, S.E., \& Russell, J.E. (1999). Newcomer Socialization and Stress: Formal peer relationships as a source of support. Journal of Vocational Behavior, 54, 453-470.

2. Barnard, C. I. (1938). The functions of the executive. Cambridge, MA: Harvard University Press.

3. Bateman, T. S., \& Organ, D. W. (1983). Job satisfaction and the good soldier: The relationship between affect and employee "citizenship". Academy of Management Journal, 26, 587-595.

4. Bocchino, C. C, Hartman, B. W., \& Foley, P. F. (2003). The relationship between person-organization congruence, perceived violations of the psychological contract, and occupational stress symptoms. Consulting Psychology Journal, 55, 203-214.

5. Bodoh M. N. (2012). Mastery of Socialization Content and Citizenship Behavior Associated with Organization and Newcomer Commitment: A Correlational Analysis. Ph.D. Thesis. Northcentral University Graduate Faculty of the School of Business and Technology Management. 
6. Burton, C. H. (2003). An Empirical Investigation of the Interrelationships of Organizational Culture, Managerial Values, and Organizational Citizenship Behaviors. Ph.D. Dissertation. George Washington University. Washington, D.C, U.S.

7. Cable D.M., \& DeRue D.S. (2002). The convergent and discriminant validity of subjective fit perceptions. Journal of Applied Psychology, 87(5), 875-884.

8. Cable, D.M., \& Parsons C.K. (2001). Socialization tactics and person-organization fit. Personnel Psychology, 54, 1-23.

9. Chao, G. T., O'Leary-Kelly, A. M., Wolfe, S., Klein, H. J., \& Gardner, P. D. (1994). Organizational socialization: Its content and consequences. Journal of Applied Psychology, 779(5), 730-743.

10.Cooper-Thomas, H.D., Vianen, A.V., Anderson, N. (2004). Changes in person-organization fit: The impact of socialization tactics on perceived and actual PO fit. European Journal of Work and Organizational Psychology, 13(I), 52-78.

11.Davis, Victoria A. (2006). Relationships among workplace fit perceptions, job satisfaction, organizational citizenship behavior, organizational commitment, and turnover intentions. Ph.D. Thesis. Alliant International University. San Diego, CA.

12.Feldman, D. C. (1981). The multiple socialization of organization members. Academy of Management Review, 6, 309-319. Retrieved from ProQuest database.

13.Feldman, D. C. (1976). A Contingency Theory of Socialization. Ph.D. Dissertation. Yale University. New Hawen, CT.

14.Fisher, C. D. (1986). Organizational socialization: An integrative review. Research in Personnel and Human Resource Management, 4, 101-145.

15.Greene-Shortridge, T. (2008). Proximal and longitudinal outcomes of person-environment fit: a positive psychological approach. Ph.D. Thesis. Clemson University. Clemson, South Carolina (2009).

16.Jones, G. R. (1986). Socialization tactics, self-efficacy, and newcomers' adjustment to organizations. Academy of Management Journal, 29(2), 262- 279.

17.Katz, D. (1964). Motivational basis of organizational behavior. Behavioral Science, 9, 131-146.

18.Klein, H. J., \& Weaver, N. A. (2000). The effectiveness of an organizational-level orientation-training program in the socialization of new hires. Personnel Psychology, 55(1), 47-66.

19.Kristof, A. L. (1996). Person-organization fit: An integrative review of its conceptualizations, measurement, and implications. Personnel Psychology, 49, 1- 49.

20.Kristof-Brown, A.L., Zimmerman, R.D., \& Johnson, E.C. (2005). Consequences of individuals' fit at work: A meta-analysis of person-job, person organization, person-group, and person-supervisor fit. Personnel Psychology, 58, 281-342.

21.Lauver, K.J., \& Kristof-Brown, A.L. (2001). Distinguishing between employees' perceptions of person-job and person-organization fit. Journal of vocational behavior, 59(3), 454-470.

22.Malamut, A. B. (2002). Socialization and Perceptual Agreement: Testing a Bottom-up Emergence Model of Organizational Climate Formation. Ph.D. Thesis. George Washington University. Washington, D.C., US.

23.Morley, J.M. (2007). Person-Organization Fit. Journal of Managerial Psychology, 22, 109-117.

24.Mosley, Jr., Donald, C. (2002). The influence of person-job fit, person-organization fit, and self-efficacy perceptions on work attitudes, job performance and turnover. Ph.D. Thesis. Mississippi State University. Mississippi, USA.

25.Motowidlo, S. J. (2000). Some basic issues related to contextual performance and organizational citizenship behavior in human resource management. Human Resource Management, 10, 115-126. Retrieved from http://www.sciencedirect.com/science/article.

26.Noe, R. A., Hollenbeck, J. R., Gerhart, B., \& Wright, P. M. (2003). Human resource management: Gaining a competitive advantage. Boston, MA: McGraw-Hill Irwin.

27.O'Reilly, C. A., Chatman, J., \& Caldwell, D. (1991). People and organizational culture: A Q-sort approach to assessing person-organization fit. Academy of Management Journal, 34(3), 487-516.

28. Organ, D. W. (1988). Organizational citizenship behavior: The good Soldier syndrome. Lexington, MA: Lexington Books.

29.Podsakoff, P. M., MacKenzie, S. B., Moorman, R., \& Fetter, R. (1990). The impact of transformational leader behaviors on employee trust, satisfaction, and organizational citizenship behaviors. Leadership Quarterly, 1, 107-142.

30.Podsakoff, P. M., MacKenzie, S. B., Paine, J., \& Bachrach, D. G. (2000). Organizational citizenship behaviors: A critical review of the theoretical and empirical literature and suggestions for future research. Journal of Management, 26(3), 513-563. 
Business Ethics and Leadership, Volume 3, Issue 1, 2019

ISSN (online) - 2520-6311; ISSN (print) - 2520-6761

31.Saks, A.M., \& Ashforth, B.E. (1997). A longitudinal investigation of the relationships between job information sources, applicant perceptions of fit, and work outcomes. Personnel Psychology, 50(2), 395-426.

32.Schein, E. H. (1971). The individual, the organization, and the career: A conceptual scheme. Journal of Applied Behavioral Science, 7, 104-426.

33.Sekiguchi, T. (2004). Person-Organization fit and person-job fit in employee selection: A review of the literature. Osaka KeidaiRonshu, 54(6), 179-196.

34.Smith, C. A., Organ, D. W., \& Near, J. P. (1983). Organizational Citizenship Behavior: Its nature and antecedents. Journal of Applied Psychology, 68(A), 653-663. doi: 10.1037/0021-9010.68.4.653.

35.Taormina, R.J. (2004). Convergent validation of two measures of organizational socialization. International Journal of Human Resource Management, 15(I), 76-94.

36.Taormina, R.J. (1997). Organizational socialization: A multidomain, continuous process model. International Journal of Selection and Assessment, 5, 29-47.

37.Van Maanen, J. (1978). People processing: Strategies of organizational socialization. Organizational Dynamics, 7(1), 19-36. doi: 10.1016/0090-2616(78)90032-3.

38.Van Maanen, J., \& Schein, E. H. (1979). Toward a theory of organizational socialization. In B. M. Staw (Ed.), Research in Organizational Behavior (vol. 1, pp. 209-264). Greenwich, CT: JAI Press.

39. Wachtfogel, M. (2009). Organizational Socialization, Person-Environment Fit, and Commitment of Recent College Graduates. Ph.D. Thesis. New York University Steinhardt School of Culture. Education and Human Development.

40.Wesson, M. J., \& Gogus, C. (2005). Shaking hands with a computer: An examination of two methods of organizational newcomer orientation. Journal of Applied Psychology, 90(5), 1018-1026. doi: 10.1037/0021-9010.90.5.1018.

41.Witt, L. A. (1998). Enhancing goal congruence: A solution to organizational politics. Journal of Applied Psychology, 83, 666-674.

42.Woo, Ha-Young (2006). Identification and validation of new employees' organizational socialization dimensions within a large bank in Korea, 67(11).

43.Yen, Wen-Shen (2012). Person-Environment Fit: Work-related attitudes and behavioral outcomes in continuing care retirement communities. Ph.D. Dissertation. Kansas State University. Kansas, USA. 


\section{Appendix}

\section{Questionnaire}

\begin{tabular}{|c|c|c|c|c|c|c|}
\hline S.NO & Statement & 1 & 2 & 3 & 4 & 5 \\
\hline & ORGANIZATIONAL SOCIALIZATION & & & & & \\
\hline 1 & I understand specific meanings of words and jargon in my trade/profession & & & & & \\
\hline 2 & I have learned how to successfully perform my job in an efficient manner & & & & & \\
\hline 3 & I have not mastered the specialized terminology and vocabulary of this organization & & & & & \\
\hline 4 & I have mastered the required tasks of my job & & & & & \\
\hline 5 & I have learned how things "really work" on the inside of this organization & & & & & \\
\hline 6 & I understand what most of the acronyms and abbreviations of my trade/profession mean & & & & & \\
\hline 7 & I understand what all the duties of my job entails & & & & & \\
\hline 8 & I know who the most influential people are in my organization & & & & & \\
\hline 9 & I would be a good resource in describing the background of my workgroup/department & & & & & \\
\hline 10 & I support the goals that are set by my organization & & & & & \\
\hline 11 & The goals of my organization are also my goals & & & & & \\
\hline 12 & I would be a good example of an employee who represents my organization's values & & & & & \\
\hline 13 & I believe that I fit well with my organization & & & & & \\
\hline 14 & I would be a good representative of my organization & & & & & \\
\hline 15 & I understand the goals of my organization & & & & & \\
\hline 16 & Within my workgroup, I would be easily identified as "one of the gang" & & & & & \\
\hline 17 & I do not have a good understanding of the politics in my organization & & & & & \\
\hline 18 & $\begin{array}{l}\text { I am not always sure what needs to be done in order to get the most desirable work assignments } \\
\text { in my area }\end{array}$ & & & & & \\
\hline 19 & I have not fully developed the appropriate skills and abilities to successfully perform my job & & & & & \\
\hline 20 & I have not yet learned "the ropes" of my job & & & & & \\
\hline 21 & I am usually excluded from social get-togethers given by other people in the organization & & & & & \\
\hline 22 & I am usually excluded from informal networks or gatherings of people within this organization & & & & & \\
\hline 23 & I do not always understand what these organizations' abbreviations and acronyms mean & & & & & \\
\hline \multirow[t]{2}{*}{24} & I have not mastered this organizations slang and special jargon & & & & & \\
\hline & ORGANIZATIONAL CITIZENSHIP BEHAVIOR & & & & & \\
\hline 1 & I keep abreast of change in the organization & & & & & \\
\hline 2 & I foster my colleagues in order to use a new method while doing their jobs & & & & & \\
\hline 3 & I encourage my colleagues who are shy for telling their opinions & & & & & \\
\hline 4 & I defend my company when it is criticized & & & & & \\
\hline 5 & I attend functions that are not required but help the company image & & & & & \\
\hline 6 & I honestly express myself about critical topics even my colleagues don't agree with me & & & & & \\
\hline 7 & I inform my supervisor before taking any important actions & & & & & \\
\hline 8 & I am always willing to cooperate with others to get a job done & & & & & \\
\hline 9 & My attendance at work is above the norm & & & & & \\
\hline 10 & I do not take extra breaks & & & & & \\
\hline 11 & I do not abuse the rights of others & & & & & \\
\hline 12 & I take steps to prevent problems with other workers & & & & & \\
\hline 13 & I help others who have been absent & & & & & \\
\hline 14 & I help others who have a heavy workload & & & & & \\
\hline 15 & I always focus on what's wrong, rather than the positive side & & & & & \\
\hline \multirow[t]{2}{*}{16} & I am always punctual & & & & & \\
\hline & PERSON-ENVIRONMENT FIT & & & & & \\
\hline 1 & My personal values match my facility's values and culture & & & & & \\
\hline 2 & My organization's values and cultures provide a good fit with the things that I value in life & & & & & \\
\hline 3 & There is a good fit between what my job offers me and what I am looking for in a job & & & & & \\
\hline 4 & The attributes that I look for in a job are well satisfied by my present job & & & & & \\
\hline 5 & My current job gives me just about everything that I want from a job & & & & & \\
\hline 6 & The things that I value in life are very similar to the things that my organization values & & & & & \\
\hline 7 & My personal values match my supervisor's values and beliefs & & & & & \\
\hline 8 & The things I value in life are very similar to the things my supervisor values & & & & & \\
\hline 9 & My supervisor's values and beliefs provide a good fit with the things I value in life & & & & & \\
\hline 10 & My abilities and training are a good fit with the requirements of my job & & & & & \\
\hline 11 & My abilities and education are in line with the demands that my job places on me & & & & & \\
\hline
\end{tabular}

